\title{
The effect of inspiratory rise times on sputum movement during ventilator hyperinflations in a test lung model
}

R. L. Chapman ${ }^{\text {a.b, }}{ }^{*}$, H.Shannon ${ }^{\text {a }}$, E. Koutoumanou ${ }^{\text {c }}$, E. Main ${ }^{\mathrm{a}}$

${ }^{a}$ Physiotherapy Programme, UCL Great Ormond Street Institute of Child Health, London, UK

${ }^{b}$ Therapy Services, Hampshire Hospital's NHS Foundation Trust, Winchester, UK ${ }^{1}$

${ }^{c}$ Population, Policy and Practice Programme, UCL Great Ormond Street Institute of

Child Health, London, UK

${ }^{1}$ Present address Therapy Services, Oxford University Hospitals NHS Foundation

Trust, Oxford, UK

Authors Email Addresses:

ruth.chapman@ouh.nhs.uk

h.shannon@ucl.ac.uk

e.koutoumanou@ucl.ac.uk

e.main@ucl.ac.uk

Corresponding Author Contact Details:

Ruth Chapman Therapy Services, Level 2, John Radcliffe, Headley Way, Headington, Oxford, OX3 9DU: +44 03003047777; E-mail address: ruth.chapman@ouh.nhs.uk

\section{Structured Abstract}

Objectives: Physiotherapists may use ventilator hyperinflation (VHI) to enhance secretion clearance for intubated patients. This study investigated the effects of altering percentage inspiratory rise time (IRT) on sputum movement, ratio of peak inspiratory to expiratory flow rate (PIF:PEF ratio) and net peak expiratory flow (PEF) during ventilator hyperinflations in a test lung model.

Design: Laboratory-based bench study.

Interventions: Simulated sputum (two viscosities) was inserted into clean, clear tubing and connected between a ventilator and a resuscitation bag. Thirty-six VHI breaths were applied for each 5\% incremental increase in IRT between $0 \%$ and $20 \%$.

Main Outcome Measures: The primary outcome was sputum displacement $(\mathrm{cm})$.

Secondary outcomes included PIF:PEF ratio and net PEF. 
Results: Significant cephalad sputum movement of $2.42 \mathrm{~cm}$ (1.59 to 3.94 ) occurred with IRT between 5-20\%, compared with caudad movement of $0.53 \mathrm{~cm}(0.31$ to 1.53$)$ at $0 \%$ IRT, (median sputum movement difference $3.7 \mathrm{~cm}(95 \%$ confidence interval 2.2 to $4.8, \mathrm{p}<0.001)$. Incremental increases in IRT percentage produced linear enhancements in PIF:PEF ratio and net PEF for both sputum concentrations, $\mathrm{p}<0.0001$. However, once the critical threshold of 0.9 PIF:PEF ratio was achieved, the distance of sputum movement remained consistent for all IRT values exceeding $5 \%$.

Conclusions: Significant increases in sputum movement occurred when the IRT percentages were lengthened to achieve the optimal PIF:PEF ratio, irrespective of sputum viscosity. This provides a theoretical rationale for therapists to consider this technique when treating mechanically ventilated patients. As no additional sputum movement was seen beyond the critical PIF:PEF ratio threshold, a low percentage IRT may potentially be used to achieve effective sputum movement.

\section{Contribution of the Paper:}

- A longer percentage inspiratory rise time creates more favourable conditions for two-phase gas liquid flow, through a reduction of inspiratory flow rate.

- Once critical flow thresholds for sputum movement are achieved, no further net benefit may occur by further increasing the percentage inspiratory rise time further.

Keywords: ventilators, mechanical; physical therapists; tidal volume; sputum; peak expiratory flow rate; flow bias 


\section{Introduction:}

Intubated patients receiving ventilatory support are at risk of sputum retention, airway occlusion and alveolar collapse, and may require physiotherapy to optimise ventilation and remove retained secretions $[1,2]$. Physiotherapists may use manual hyperinflation and ventilator hyperinflation (VHI) to increase tidal volumes and peak expiratory flow rate (PEF) in order to recruit atelectatic areas or to enhance airway secretion clearance $[1,3,4,5]$.

Estimates of PEF during both manual and ventilator hyperinflation, range from 27.8 litres/minute $(\mathrm{L} / \mathrm{min})$ to $120 \mathrm{~L} / \mathrm{min}[6,7,8]$. These values do not approach the peak flows produced during huffing or coughing (360-720L/min) [9], so cannot be said to be effective via the same propulsive method of airflow. Instead, sputum clearance via manual and ventilator hyperinflation is likely to depend upon two-phase gas liquid flow interactions, whereby, airflow creates a shearing force upon the liquid surface creating annular waves in the direction of the airflow $[10,11,12]$. For net sputum movement towards the mouth (cephalad) to occur, the shear forces must exceed gravitational and viscous resistance, with an overall expiratory flow bias, which exceeds a critical threshold. The critical thresholds suggested in published literature to date have been either a ratio between the peak inspiratory flow and expiratory flow rates (PIF:PEF ratio) of $<0.9$, in which PEF exceeds the PIF by at least $10 \%$ $[11,13,14,15]$, or by which the PEF exceeds the PIF (net PEF) by $17 \mathrm{~L} / \mathrm{min}$, under laboratory conditions [16].

Savian et al. [7] found that the PIF:PEF ratio was higher using VHI compared to manual hyperinflation, with VHI achieving a ratio of 1.27 (i.e. favouring the 
inspiratory flow of air). This suggested that VHI may promote a caudad movement of sputum, embedding sputum into the lungs, rather than towards the mouth. Findings may, in part, have been due to the VHI method, which involved delivering large tidal volume breaths with a short inspiratory time. Subsequently, a bench top VHI investigation found that reducing inspiratory flow was associated with successfully achieving critical expiratory flow thresholds [17]. However, this inspiratory flow setting feature is not available on all ventilators. Other mechanical ventilation studies suggested that reducing PIF by increasing the inspiratory: expiratory (I:E) time ratio and inspiratory rise times may also create more favourable net PEF, PIF:PEF ratio and net cephalad sputum movement $[15,18,19,20]$. The purpose of this study was to investigate the effects of different inspiratory rise time (IRT) percentage settings during VHI, in order to identify:

- the effect of different IRT percentages on the movement of sputum, PIF:PEF ratio and net PEF during ventilator hyperinflation, and

- whether the movement of different viscosities of sputum (1.5\% and $3 \%)$ was similar for each experimental condition.

\section{Methods}

\section{Design}

This experimental laboratory-based bench study was approved by the UCL Institute of Child Health and Great Ormond Street Hospital for Children NHS Foundation Trust joint research and development committee, research and development number $13 \mathrm{~A} 12$.

\section{Equipment}

The experimental setup was designed to emulate sputum within the adult trachea 
during both mechanical ventilation and VHI. To achieve this, a mechanical ventilator (Servo-i Universal, Maquet, Stockholm, Sweden) was attached to a 30cm length of clear and transparent polyvinyl-chloride (PVC) tubing (RSonline, Corby, UK) with an internal diameter of 10mm, via a non-humidified circuit (Kimberley Clarke, Texas, USA) and size 8, cuffed endotracheal tube (Portex, Minneapolis, USA) [16]. The tubing, which represented the trachea, was positioned horizontally on a flat white surface using a spirit level. The remaining end of the $30 \mathrm{~cm}$ tube was attached to a two litre inflatable resuscitation bag (Datex Omeda, General Electric, Madison, USA) representing the lungs. This had a measured compliance of $15.5 \mathrm{~mL} / \mathrm{cmH}_{2} 0$. All tubing was connected with plastic connectors with a negligible air leak (Figure 1).

A mucus simulant was prepared using polyethylene oxide powder (Sentry Polyox WSR coagulant, Dow, Delaware) and water to create a water-soluble resin coagulant, which has been used in a previous bench study [16]. A 1.5\% solution was used to represent normal viscosity sputum and a 3\% solution represented viscous sputum, simulating that found in lung disease [16]. To create a $1.5 \%$ solution, $1.5 \mathrm{~g}$ of powder was mixed with $100 \mathrm{~mL}$ of boiling distilled water and stirred continuously on a combined hotplate with magnetic stirrer to create a solution with consistent viscosity. An equivalent procedure, using $3 \mathrm{~g}$ of the powder mixed with $100 \mathrm{~mL}$ of water was undertaken to produce the $3 \%$ solution. Both samples were coloured using red food dye to allow photographic imaging and subsequent analysis. Using a syringe, one $\mathrm{mL}$ of the sputum was injected into the middle of a new PVC tubing segment, for each experiment.

Equipment for recording mucus movement and airflow 
Mucus movement was captured using an 18-megapixel Cannon 600d camera, placed $40 \mathrm{~cm}$ above the sputum sample by use of a tripod perpendicular to the sputum specimen. Baseline mechanical ventilation was undertaken for two minutes, after which an image was captured during expiration. Baseline ventilation allowed the sputum to settle, providing a consistent baseline between datasets and exposing the sputum to the normal shearing forces that occur during tidal volume ventilation. Next, 36 'breaths' of VHI were applied and a second image was recorded during expiration.

Software (Sigmascan Pro 5, stat Software Inc, London) was used to evaluate the movement of simulated sputum between the end of baseline ventilation and following the VHI intervention. The software measured sputum area and depth by determining the number of red pixels within each square $\mathrm{cm}$ and calculating the movement of the sputum centre of mass from the VHI.

The $\mathrm{CO}_{2} \mathrm{SMO}^{\circledR}$ Plus 8100 Respiratory Profile Monitor (Novametrix Medical Systems Inc, Philips Respironics, Wallingford, CT, USA) was used to measure tidal volume, respiratory rate, PIF, PEF and peak inspiratory pressure continuously, via a fixed orifice differential flow-pressure transducer. The $\mathrm{CO}_{2} \mathrm{SMO}^{\circledR}$ was positioned between the endotracheal tube and catheter mount and connected to a laptop to record data (Figure 1). To ensure data accuracy, the $\mathrm{CO}_{2} \mathrm{SMO}^{\circledR}$ was calibrated prior to the experiment using a 500mL calibration syringe (Hans Rudolph Inc, Kansas USA) using volumes of $300 \mathrm{mLs}, 400 \mathrm{mLs}$, and 500mLs. Measurement within 5\% of delivered volume was deemed as appropriately accurate for the study. The $\mathrm{CO}_{2} \mathrm{SMO}^{\circledR}$ has previously been validated over this volume range and has been used in 
both clinical practice and research [21,22].

\section{Intervention}

Baseline ventilation was delivered in pressure regulated volume control mode with positive end expiratory pressure of $5 \mathrm{cmH}_{2} \mathrm{O}$, an I:E time ratio of $1: 2$ and a IRT of $5 \%$. These settings were considered to be consistent with routine clinical care [23,24]. A baseline tidal volume of $370 \mathrm{~mL}$ during mechanical ventilation was applied. This volume was calculated using the ARDSNet protocol for a targeted $6 \mathrm{~mL} / \mathrm{Kg}$ of the predicted body weight [25] by using the average UK height [26]. VHI was delivered by increasing the tidal volume until the peak airway pressure reached $40 \mathrm{cmH}_{2} \mathrm{O}$, in line with previous clinical studies $[4,27,28]$. During testing of the experimental setup this volume was calculated to be between $550-700 \mathrm{mLs}$. To provide a consistent minute volume, the respiratory rate was reduced to $8 \mathrm{bpm}$ when the IRT percentage was also changed. This reduction was similar to previous clinical studies and prevented the impact of elastic recoil and airway flows that would have occurred with a higher minute volume [7,28].

The IRT was manipulated using the IRT percentage control, as this was the most straightforward option to modify the IRT in this volume control mode. The IRT percentage was set at either a $0 \%, 5 \%, 10 \%, 15 \%$ or $20 \%$ intervals at $5 \%$ intervals between $0 \%$ and $20 \%$ (Table 1), for 36 consecutive breaths. VHI breaths started immediately after the respiratory rate and the IRT percentage were altered. Each experiment was completed three times, for each of the 10 experimental conditions, with new tubing and sputum injection used for each experimental condition. The experiment was conducted by a physiotherapist who had specialised within the 
respiratory field for approximately eight years.

Data Analysis

The $\mathrm{CO}_{2} \mathrm{SMO}^{\circledR}$ respiratory monitor was internally programmed to deploy brief automatic calibration 'purges' at regular two minute intervals, during which times respiratory measurements were not possible (approximately 2-3 seconds). Data from the $\mathrm{CO}_{2} \mathrm{SMO}^{\circledR}$ were examined and calibration purge intervals were excluded. Nonparametric tests were used to analyse the data sets for each experiment. The comparison of sputum movement across the range of IRT percentages were analysed using a Kruskal Wallis ANOVA and the comparison between sputum viscosity types was calculated by Mann-Whitney U tests. To determine whether there was a difference of PIF, PEF, PIF:PEF ratio and net PEF between the IRT ranges, the Kruskal Wallis ANOVA was used with post-hoc analysis where appropriate. The Spearman's Rank Test was used to ascertain any correlation between the PIF:PEF ratio and net PEF with the IRT percentage. The level of significance was set at $\mathrm{p}<0.05$ and, where appropriate, the data displayed as medians with interquartile range or means and standard deviation with $95 \%$ confidence interval.

\section{Results}

\section{Management of Data}

Each dataset was examined and measurements affected by the purging process were removed. Six to seven breaths were required to reach a steady state at the predetermined VHI levels, these were excluded from the data analysis. An average of 29 
VHI breaths per experiment were used for statistical analysis. The experimental settings are displayed in Table 1.

\section{Observed Sputum Movement}

The Krusal Wallis Anova detected a significant difference between the IRT percentage groups $(\mathrm{p}<0.05)$ but further analysis showed there were no significant differences in sputum movement between groups for any IRT between 5\% and 20\%

(Figure 2). Significant cephalad sputum movement of $2.42 \mathrm{~cm}$ (1.59 to 3.94$)$ occurred with IRT between $5 \%$ or more, across both sputum viscosities, compared with caudad movement of $0.53 \mathrm{~cm}(0.31$ to 1.53$)$ at $0 \%$ IRT across both viscosities, (median sputum movement difference $3.7 \mathrm{~cm}(95 \%$ confidence interval 2.2 to $4.8, \mathrm{p}<0.001)$. Normal viscosity sputum consistently moved significantly further than higher viscosity sputum for all VHI settings (Table 2). The median difference in sputum movement between the $1.5 \%$ and $3.0 \%$ sputum viscosities was $2.31 \mathrm{~cm}(1.61,2.96$, $\mathrm{p}=0.004)$.

\section{PIF:PEF Ratios and Net PEF}

As the IRT systematically increased between $0 \%$ and $20 \%$, PEF did not change significantly $(\mathrm{p}=0.151)$, but PIF reduced significantly with both sputum viscosities as the percentage IRT lengthened, $(\mathrm{p}<0.001)$ (Table 2$)$. Consequently, there was a strong, negative correlation $(\mathrm{r}=-0.982, \mathrm{p}<0.0001)$, between mean PIF:PEF ratio and the increased IRT percentage for both sputum samples during VHI. The PIF:PEF ratio dropped below the theoretical critical threshold of 0.9 for cephalad sputum movement between $0 \%$ and 5\% IRT and then decreased further for each subsequent $5 \%$ increase in IRT, suggesting that mucous movement would be linearly enhanced 
by increasing the IRT percentage (Figure 3). There was a statistically significant difference of $\mathrm{p}<0.01$ in PIF:PEF ratios when the IRT differed by more than $10 \%$, for both sputum viscosities.

Similarly, there was a strong, positive correlation between net PEF and the increase in IRT percentage ( $r=0.972, p<0.0001$ for both sputum viscosities). The theoretical net PEF threshold of greater than $17 \mathrm{~L} /$ min was achieved when the IRT percentage increased to $10 \%$ or more, suggesting that mucus movement would be linearly enhanced in relation to IRT percentage as long as IRT exceeded 10\% (Figure 4). There was a significant difference in net PEF when the IRT percentage increased by more than $10 \%$ for both sputum viscosities, $\mathrm{p}<0.01$.

\section{Discussion}

This is the first study to investigate whether altering the IRT percentage during VHI can improve the expiratory flow bias and cephalad net sputum movement in ventilated patients. The main finding was that cephalad movement of sputum could be observed for all IRT values meeting or exceeding $5 \%$, and retrograde sputum movement was likely when IRT was set at $0 \%$. Furthermore, despite the published theoretical models predicting a linear relationship between sputum movement and PIF:PEF ratio or net PEF, once critical thresholds were achieved, no further enhancement was observed in sputum movement for any IRT values meeting or exceeding 5\%. Finally, normal viscosity sputum moved significantly further than thicker sputum for all percentages of IRT, either in a retrograde direction (when IRT was set at $0 \%$ ) or in a cephalad direction (when IRT was set at $5 \%, 10 \%, 15 \%$ or $20 \%)$. 
Given the strong relationships between increasing IRT percentage and both PIF:PEF ratio and net PEF, sputum movement might be expected to be further enhanced with each 5\% incremental increase in IRT in a systematic and predictable manner (Figures $3 \& 4$ ). However, sputum movement appeared to plateau for all IRT values between 5 and 20\%, despite conditions exceeding the threshold criteria for sputum movement (Figures $2 \& 5$ ). Factors such as insufficient breath numbers at the full VHI volume, crude measurement of sputum movement or inability of the PVC tube to represent a ciliated humidified airway, may have contributed to the lack of differentiation in sputum movements between 5 and 20\% IRT. However, the most likely rationale is related to the flow thresholds. Annular flow occurs when airflow exceeds 6-20L/min and formation of mist flow occurs at a threshold of 50L/min airflow or above $[10,11,13,14,29]$. The highest peak flows achieved during this study measured 79L/min, well below the threshold required for mist flow. This may explain why the sputum movement did not continuously increase between 5 and 20\% IRT in the manner suggested by the PIF:PEF ratio and net PEF graphs. This result contrasts with Kim et al's study, which detected a linear relationship between the rate of airflow and speed of mucus movement, although they used continuous uni-directional airflow for their study [30].

Net PEF exceeded the threshold of $17 \mathrm{~L} / \mathrm{min}$ when the IRT was increased to $10 \%$ and above, whilst generation of the PIF:PEF ratio of $<0.9$ occurred for all data points between 5\% and 20\% IRT. Comparing these two threshold requirements for twophase gas liquid flow, it is clear that the PIF:PEF ratio of 0.9 predicted mucus movement more accurately than the net PEF of $17 \mathrm{~L} / \mathrm{min}$, despite similarities in the 
methods used by Volpe and colleagues and the current study [16]. The 17L/min threshold has not been reproduced by any other authors. Conversely, research examining PIF:PEF ratios utilised the theory of fluid mechanics to provide a mathematical modeling solution applicable to multiple conditions of two-phase gas liquid flow and therefore may be more generalisable to other settings [13,14].

Both types of sputum moved in the same direction in response to the changes in the IRT percentage. This is clinically relevant, demonstrating that sputum may behave in a similar manner over a range of viscosities and does not require different conditions in order to promote cephalad movement. The greater movement of the normal viscosity sputum is consistent with previous studies as well as clinical practice $[11,13,14,16]$, signifying that mucus of a lower viscosity will respond more quickly during VHI interventions.

During the volume control mode, the IRT percentage is the percentage of time taken to reach peak inspiratory flow over the respiratory cycle. Both the increase in the IRT percentage and reduction of the respiratory rate will increase the calculated IRT as measured in seconds (Table 1). These figures are estimates, due to ventilator variability to achieve the desired maximal flow within preset time [31]. Both the length of the IRT (as measured in seconds) as well as the pulmonary airway pressure will generate the resultant PIF. Although favourable PIFs were achieved at only a 5\% IRT during these experimental VHI conditions, if the respiratory rate was higher, the percentage IRT may have to be manipulated further to optimise the PIF. 
The laboratory-based bench experimental design was chosen as it permitted proof of concept analysis of multiple experimental conditions. These were tested to identify methods of improving the effectiveness of VHI, without the need to involve patients in the first instance. The lung model excluded physiological variations and therefore controlled for potential confounding factors which would occur in the clinical environment. However, a laboratory-based study with a fixed diameter tube and inflatable bag cannot exactly replicate normal patient physiology (i.e. multiple airway branching, dynamic airway compression, collateral ventilation, lung hysteresis, variable lung unit compliance, mucociliary escalator, non-uniform sputum viscosity and so forth). This model was unable to reproduce the layers within the airway surface liquid or the cilial movement and instead focused upon dry gas flow upon homogenous sputum. The impact of humidity upon the viscous and elastic properties of simulated sputum has not been accounted for. Additionally, the simulated trachea was placed horizontally rather than at the 30-degrees head up position utilised clinically. Consequently, the additional force required to move sputum upwards was not reproduced, potentially reducing the flow thresholds at which sputum movement occurred and/or increased the resulting sputum movement at the set percentage IRT. Due to the experimental method using a tube with an inner diameter of $10 \mathrm{~mm}$, these results cannot be generalised to bronchial clearance.

This method of enhancing VHI through alteration of the IRT percentage, provides a theoretical rationale to improve tracheal sputum clearance in clinical practice. The potential negative side effects of an inappropriately long IRT percentage could include patient-ventilator asynchrony and consequential discomfort. However, most patients requiring a volume control mode are sedated and such effects are small in 
magnitude, easy to identify and quick to reverse. Given that an optimal PIF:PEF ratio was achieved at a conservative IRT percentage, it should be feasible to achieve an optimal balance between patient comfort and effective sputum movement. Further analysis of the PIF:PEF ratios during VHI in clinical practice to ascertain whether the $\mathrm{PIF}: \mathrm{PEF}<0.9$ threshold is achieved at a conservative IRT percentage in patients with higher lung compliance, could prove useful.

This study confirms that increasing the percentage IRT results in a favourable PIF:PEF ratio and increases the net PEF within a test lung model, through a reduction in PIF. This creates conditions that theoretically promote two-phase gas liquid flow of cephalad mucus movement, and therapeutic tracheal clearance. However, once critical thresholds for sputum movement are achieved, no further net benefit is seen by further increasing the percentage IRT. During this study, effective cephalad sputum movement occurred when the IRT percentage was set between 5 and $20 \%$. Therefore, clinicians are encouraged to analyse the PIF and PEF outcomes generated during VHI and consider lengthening the percentage IRT to optimise their treatment whilst monitoring patient comfort and synchrony.

Ethical approval: Ethical approval was not required for this laboratory-based bench study. The study was registered with the by Great Ormond Street Hospital for Children NHS Trust and University College London, Institute of Child Health Research Ethics Committee, Research and Development Number 13A12. 
Funding: This research did not receive any specific grant from funding agencies in the public, commercial or not-for-profit sector and was completed as part of an MSc dissertation.

Conflict of interest: None declared. 


\section{REFERENCES}

[1] Branson RD. Secretion management in the mechanically ventilated patient. Respir Care 2007; 52:1328-42.

[2] Gosselink R, Bott J, Johnson M, Dean E, Nava S, Norrenberg M, et al. Physiotherapy for adult patients with critical illness: recommendations of the European Respiratory Society and European Society of Intensive Care Medicine Task Force on Physiotherapy for Critically Ill Patients. Intensive Care Med 2008; 34:118899. doi: 10.1007/s00134-008-1026-7

[3] Paulus F, Binnekade J, Vroom M, Schultz M. Benefits and risks of manual hyperinflation in intubated and mechanically ventilated intensive care unit patients:a systematic review. Crit Care 2012; 16:R145. doi 10.1186/cc11457

[4] Berney S, and Denehy L. A comparison of the effects of manual and ventilator hyperinflation on static lung compliance and sputum production in intubated and ventilated intensive care patients. Physiother Res Int 2002; 7:100-8.

[5] Anderson A, Alexanders J, Sinani C, Hayes S, Fogarty M. Effects of ventilator vs manual hyperinflation in addults receiving mechanical ventilation: a systematic review of randomised clinical trials. Physiotherapy 2015; 101:103-110. doi 10.1016/j.physio.2014.07.006.

[6] MacLean D, Drummond G, Macpherson C, McLaren G, Prescott R. Maximum expiratory flow during chest physiotherapy on ventilated patients before and after the application of an abdominal binder. Intensive Care Med 1989; 15:396-9.

[7] Savian C, ParatzJ, Davies A. Comparison of the effectiveness of manual and ventilator hyperinflation at different levels of positive end-expiratory pressure in 
artificially ventilated and intubated intensive care patients. Heart Lung 2006; 35: 33441. doi: 10.1016/j.hrtlng.2006.02.003

[8] Maxwell L, Ellis E. The effect of expiratory flow rate of maintaining bag compression during manual hyperinflation. Aust J Physiother 2004; 14:199-210. [9] Leiner GC, Abramowitz S, Small MJ, Stenby VB, Lewis WA. Expiratory Peak flow rate. Standard values for normal subjects. Use as a clinical test of ventilatory function. Am Rev Respir Dis 1963; 88:644-51.

[10] Maxwell L, Ellis E. Secretion clearance by manual hyperinflation: Possible mechanisms. Physiother Theory Pract 1998; 14:189-97.

[11] Kim CS, Rodriguez CR, Eldridge MA, Sackner MA. Criteria for mucus transport in the airways by two-phase gas-liquid flow mechanism. J Appl Physiol 1986; 60:901-7. doi 10.1152/jappl.1986.60.3.901

[12] King M, Brock G, Lundell C. Clearance of mucus by simulated cough. J Appl Physiol 1985; 58:1776-85. doi: 10.1152/jappl.1985.58.6.1776

[13] Kim CS, Iglesias AJ, Sackner MA. Mucus clearance by two-phase gas-liquid flow mechanism: asymmetric periodic flow model. J Appl Physiol 1987; 62:959- 71. doi: 10.1152/jappl.1987.62.3.959

[14] Jones AY. Secretion movement during manual lung inflation and mechanical ventilation. Respir Physiol Neurobiol 2002; 132:321-327.

[15] Benjamin R, Chapman G, Kim C, Sackner M. Removal of bronchial secretions by two-phase gas-liquid transport. Chest 1989; 95:658- 63 .

[16] Volpe MS, Adams AB, Amato MBP, Marini JJ. Ventilation patterns influence airway secretion movement. Respir Care, 2008; 53:1287-1294. 
[17] Thomas P. The effect of mechanical ventilator settings during ventilator hyperinflation techniques: a bench top analysis. Anaesth Intensive Care 2015; 43:817.

[18] Bassi G, Saucedo L, Marti JD, Rigol M, Esperatti M, Luque N, et al. Effects of duty cycle and positive end-expiratory pressure on mucus clearance during mechanical ventilation. Crit Care Med 2012; 40: 895-902. doi:

10.1097/CCM.0b013e318236efb5

[19] Ntoumenopoulos G, Shannon H, Main E. Do commonly used ventilator settings for mechanically ventilated adults have the potential to embed secretions or promote clearance? Respir Care 2011; 56:1887-92. doi: 10.4187/respcare.01229

[20] Gonzales JF, Russian CJ, Marshall SG, Collins KP, Farmer TA. Comparing the effects of rise time and inspiratory cycling criteria on 6 different mechanical ventilators. Respir Care 2013; 58:465-473. doi: 10.4187/respcare.01345

[21] Main E, Castle R, Stocks J, James I, Hatch D. The influence of endotracheal tube leak on the assessment of respiratory function in ventilated children. Intensive Care Med 2001; 27:1788-97. doi: 10.1007/s001340101105

[22] Gregson R, Shannon H, Stocks J, Cole T, Peters M, Main E. The unique contribution of manual chest compression-vibrations to airflow during physiotherapy in sedated fully ventilated children. Pediatr Crit Care Med 2012; 13:97-102. doi:

10.1097/PCC.0b013e3182230f5a

[23] Hasan A. Understanding mechanical ventilation: A practical handbook. 1st ed. London: Springer Verlafg. 2010 p. 119, 124.

[24] Wilkins RL, Stoller JK, Scanlan CL. Egan's Fundamentals of Respiratory Care. 8th ed. Missouri: Mosby Inc. 2003 p. 44-9. 
[25] The Acute Respiratory Distress Syndrome Network. Ventilation with lower tidal volumes as compared with traditional tidal volume for acute lung injury and the acute respiratory distress syndrome. N Engl J Med 2000; 342:1301-4. doi:

10.1056/NEJM200005043421801

[26] Office for National Statistics. 2010. Regional trends online; September 2010. http://www.ons.gov.uk/ons/publications/re-reference-tables.html?edition=tcm\%3A77254239 [Accessed 6 February 2013]

[27] Lemes DA, Zin WA, Guimaraes FS. Hyperinflation using pressure support ventilation improves secretion clearance and respiratory mechanics in ventilated patients with pulmonary infection: a randomised crossover trial. Aust J Physiother $2009 ; 55: 249-54$.

[28] Dennis D, Jacob W, Budgeon C. Ventilator versus manual hyperinflation in clearing sputum in ventilated intensive care unit patients. Anaesth Intensive Care $2012 ; 40: 142-9$.

[29] Clarke SW, Jones JG, Oliver DR. Resistance to two-phase gas-liquid flow in airways. J Appl Physiol 1970; 29:464-71.

[30] Kim CS, Greene MA, Sankaran S, Sackner MA. Mucus transport in the airways by two-phase gas liquid flow mechanism: continuous flow model. J Appl Physiol 1986; 60:908-17. doi: 10.1152/jappl.1986.60.3.908

[31] Thille AW, Lyazidi A, RichardJC, Galia F, Brochard L. A bench study of intensive-care-unit ventilators: new versus old and turbine-based versus compressed gas-based ventilators. Intensive Care Med 2009; 35(8):1368-76. doi: $10.1007 / \mathrm{s} 00134-009-1467-7$ 


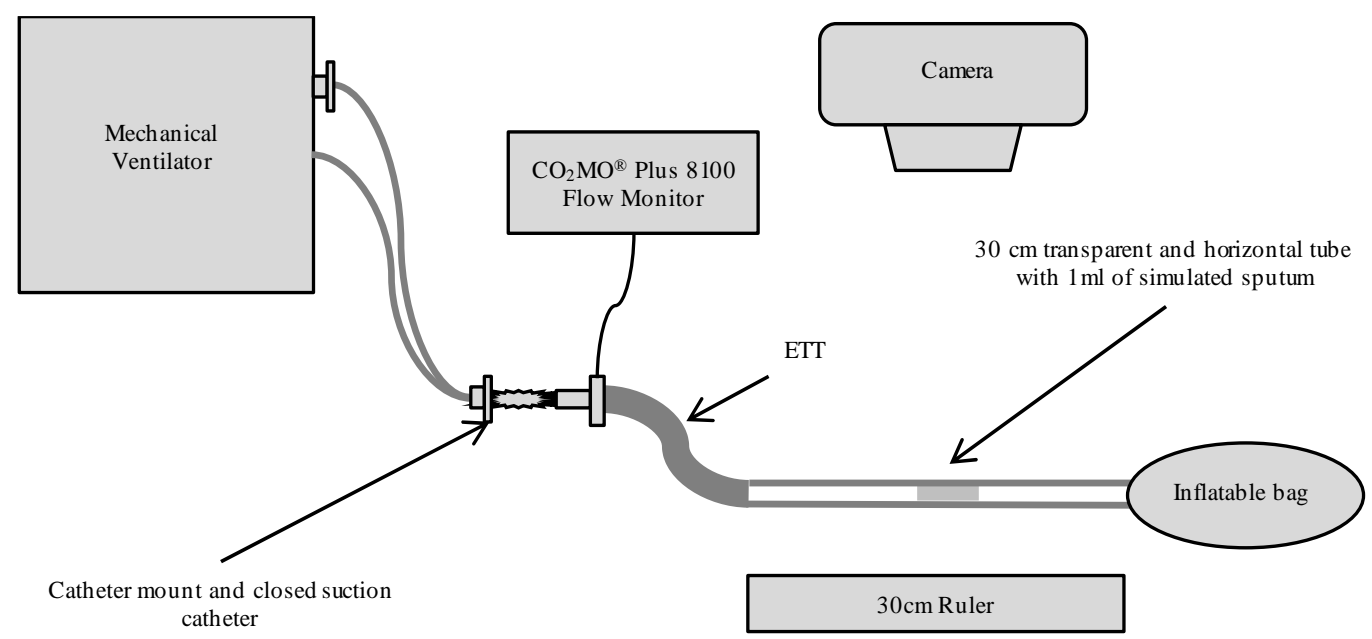

Figure 1: Experimental setup for bench study

ETT: Endotracheal tube 
Table 1: Experimental Settings

\begin{tabular}{lll}
\hline & Baseline Ventilation & Experiment Settings \\
\hline Ventilator Mode & PRVC & PRVC \\
$\mathrm{V}_{\mathrm{T}}(\mathbf{m L})$ & 370 & $550-700$ \\
Respiratory Rate (bpm) & 15 & 8 \\
PEEP (cmH $\mathbf{2})$ & 5 & 5 \\
I:E Ratio & $1: 2$ & $1: 2$ \\
Inspiratory Rise Time (\%) & $5 \%$ & $0 \%, 5 \%, 10 \%, 15 \%, 20 \%$ \\
Inspiratory Rise Time (secs)* & 0.2 & $<0.1,0.35,0.75,1.13,1.5$ \\
Length of Ventilation & 2 minutes & 36 breaths \\
PAP (cmH & & 40 \\
Mucus Viscosity & 25 & $1.5 \%$ and 3\% \\
\hline
\end{tabular}

I:E Ratio: Inspiratory: Expiratory ratio. PAP: Peak Airway Pressure. PEEP: Positive End Expiratory Pressure. PRVC: Pressure Regulated, Volume Controlled. $\mathrm{V}_{\mathrm{T}}$ : Tidal volume.

*Estimated number as variable dependent upon ventilator gas flow acceleration and additionally time is required to accelerate ad deliver gas flow even when the percentage IRT is set at $0 \%$. 


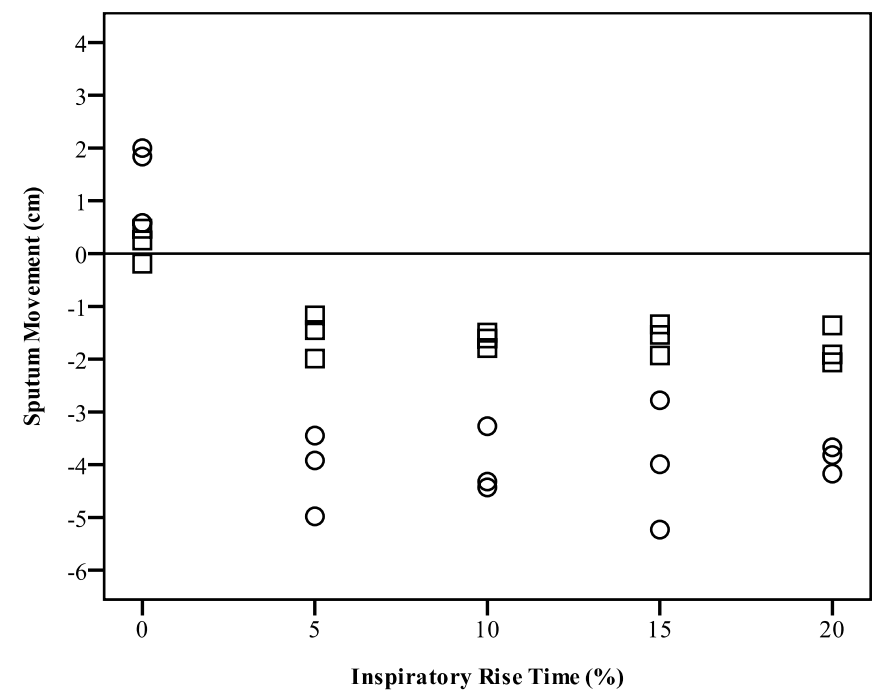

Figure 2: Sputum Movement plotted against change in inspiratory rise time during ventilator hyperinflation with $1.5 \%$ (circle) and $3 \%$ (square) sputum viscosities.

The ' 0 ' reference line denotes no movement in either direction. Negative movement indicates cephalad movement towards the mouth 


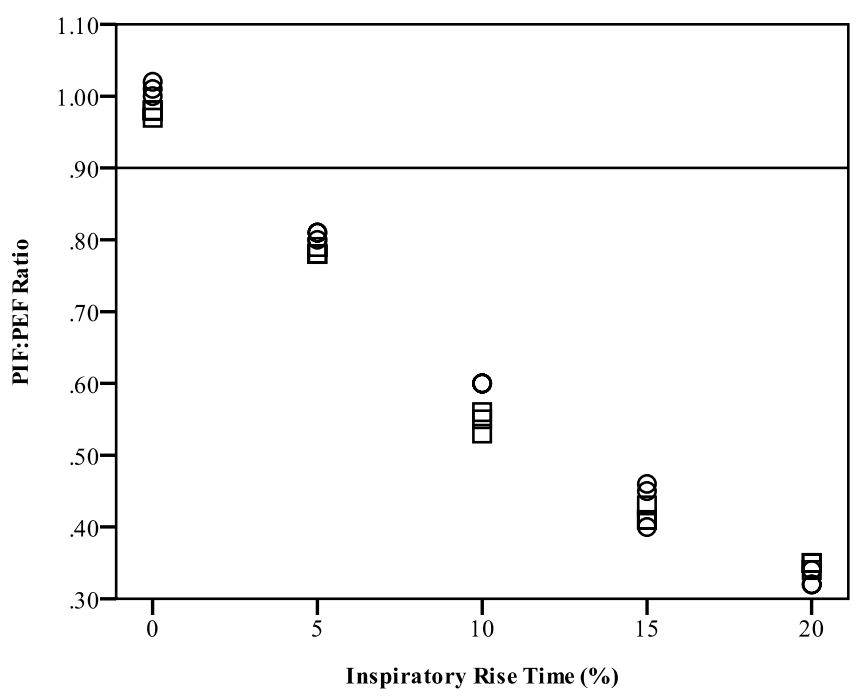

Figure 3: Peak inspiratory to expiratory flow rate (PIF:PEF) ratios plotted against change in inspiratory rise time during Ventilator Hyperinflation (VHI) with 1.5\% (circle) and 3\% (square) sputum viscosities.

The reference line at 0.9 describes the threshold PIF:PEF below which net sputum movement is expected. 


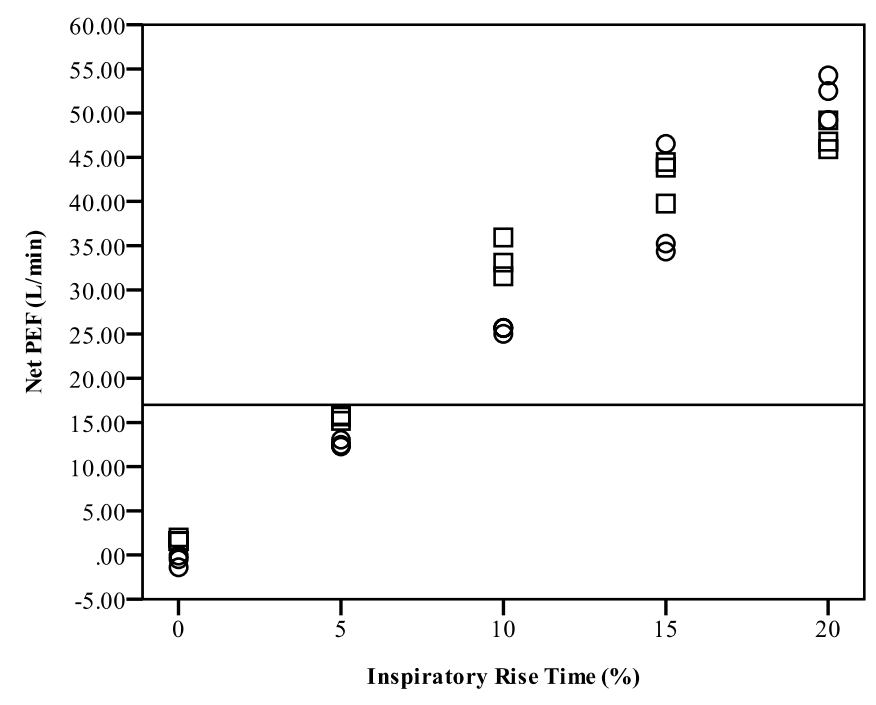

Figure 4: Net peak expiratory flow (PEF) plotted against change in inspiratory rise times during ventilator hyperinflation with $1.5 \%$ (circle) and $3 \%$ (square) sputum viscosities.

The reference line at 17L/min describes the threshold above which net sputum movement is predicted. 


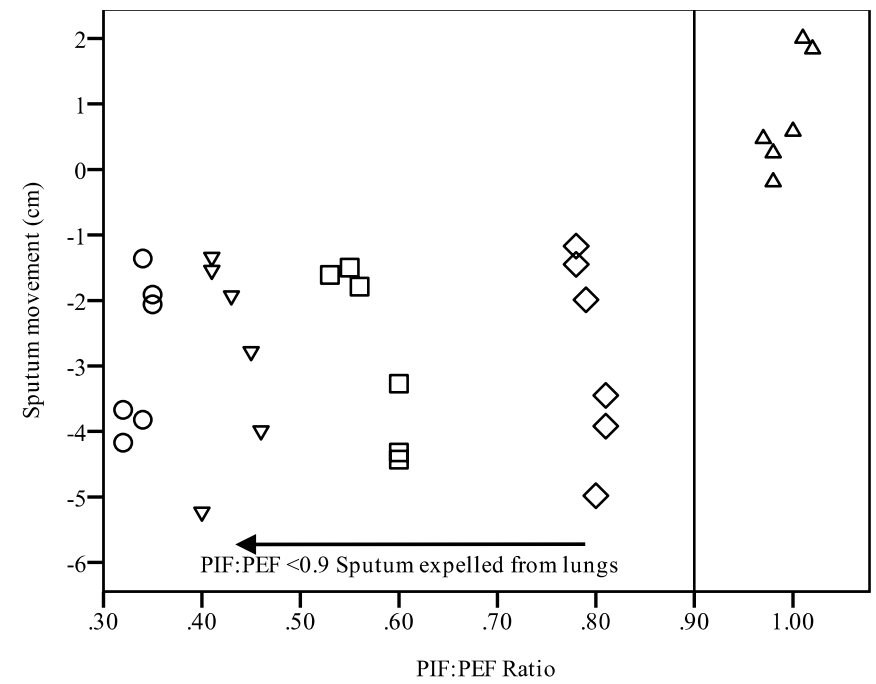

Figure 5: Peak inspiratory to peak expiratory flow rate ratios PIF:PEF) plotted against sputum movement during ventilator hyperinflation at the differing percentage inspiratory rise times

The reference line at 0.9 describes the threshold above which net sputum movement is predicted.

Circles represent data outcomes gathered using a $20 \%$ percentage inspiratory rise time Downward triangles represent data outcomes gathered using a 15\% percentage inspiratory rise time Squares represent data outcomes gathered using a 10\% percentage inspiratory rise time Diamonds represent data outcomes gathered using a 5\% percentage inspiratory rise time Upward triangles represent data outcomes gathered using a $0 \%$ percentage inspiratory rise time 
Table 2: Sputum movement and airflow measurements captured at different inspiratory rise times using $1.5 \%$ and $3 \%$ sputum viscosities

\begin{tabular}{|c|c|c|c|c|c|c|}
\hline IRT & $\begin{array}{l}\text { Sputum Viscosity } \\
(\%)\end{array}$ & $\begin{array}{l}\text { PEF }(\mathrm{L} / \mathrm{min}) \\
\text { Mean }(\mathrm{SD})\end{array}$ & $\begin{array}{l}\text { PIF (L/min) } \\
\text { Mean (SD) }\end{array}$ & $\begin{array}{l}\text { PIF:PEF Ratio } \\
\text { Mean (SD) }\end{array}$ & $\begin{array}{l}\text { PEF-PIF } \\
\text { Mean (SD) }\end{array}$ & $\begin{array}{l}\text { Sputum Movement } \\
(\mathrm{cm}) \\
\text { Median (IQR) }\end{array}$ \\
\hline \multirow{2}{*}{$\begin{array}{l}\text { Baseline } \\
\text { Ventilation }\end{array}$} & 1.5 & $49.30(3.52)$ & $44.65(2.32)$ & $0.91(0.03)$ & $4.64(1.80)$ & \\
\hline & 3 & $51.24(2.85)$ & $47.49(1.43)$ & $0.92(0.05)$ & $3.75(2.47)$ & \\
\hline \multirow[t]{2}{*}{$0 \%$} & 1.5 & $63.13(1.25)$ & $63.77(1.38)$ & $1.01(0.03)$ & $-0.64(1.69)$ & $+1.47(1.21$ to 1.92$)$ \\
\hline & 3 & $72.23(1.97)$ & $70.52(1.43)$ & $0.98(0.03)$ & $1.71(2.30)$ & $+0.18(0.03$ to 0.36$)$ \\
\hline \multirow[t]{2}{*}{$5 \%$} & 1.5 & $64.72(1.04)$ & $52.14(0.42)$ & $0.81(0.01)$ & $12.57(0.99)$ & $-4.12(-4.45$ to -3.69$)$ \\
\hline & 3 & $71.40(1.71)$ & $55.56(0.47)$ & $0.78(0.02)$ & $15.54(1.75)$ & $-1.54(-1.72$ to -1.31$)$ \\
\hline \multirow[t]{2}{*}{$10 \%$} & 1.5 & $63.57(1.19)$ & $38.11(0.28)$ & $0.60(0.01)$ & $25.45(1.20)$ & $-4.01(-4.38$ to -3.80$)$ \\
\hline & 3 & $74.02(2.42)$ & $40.49(0.25)$ & $0.55(0.02)$ & $33.54(2.44)$ & $-1.63(-1.70$ to -1.56$)$ \\
\hline \multirow[t]{2}{*}{$15 \%$} & 1.5 & $68.39(6.16)$ & $29.69(0.54)$ & $0.44(0.03)$ & $38.70(5.67)$ & $-4.00(-4.61$ to -3.39$)$ \\
\hline & 3 & $73.16(2.74)$ & $30.49(0.19)$ & $0.42(0.02)$ & $42.68(2.68)$ & $-1.60(-1.74$ to -1.44$)$ \\
\hline \multirow{2}{*}{$20 \%$} & 1.5 & $76.97(2.36)$ & $24.96(0.21)$ & $0.32(0.01)$ & $52.01(2.31)$ & $-3.89(-4.00$ to -3.75$)$ \\
\hline & 3 & $71.79(3.33)$ & $24.68(1.36)$ & $0.34(0.01)$ & $47.11(2.47)$ & $-1.78(-1.99$ to -1.64$)$ \\
\hline
\end{tabular}

The movement of sputum towards the ETT is denoted by a descending, more negative value, and the caudad movement is indicated by an ascending, positive value.

IQR: Interquartile range, IRT: Inspiratory rise time, PIF: Peak inspiratory flow, PEF: Peak expiratory flow, PIF:PEF Ratio: Peak inspiratory flow : Peak expiratory flow ratio, PEF-PIF: Peak expiratory flow - peak inspiratory flow, SD: Standard deviation 